\title{
COVID-19 in patients aged 80 years and over during the peaks of the first three pandemic waves at a Spanish tertiary hospital
}

Catia Cilloniz¹, Fernanda Meira², Gerad Dueñas², Julia V. Gimeno-Miron², Mariana Chumbita², Pedro Puerta-Alcalde ${ }^{2}$, Nicole Garcia-Pouton², Albert Gabarrus ${ }^{1}$, Veronica Rico², Antoni Torres ${ }^{1}$, Carolina Garcia-Vidal², Alex Soriano ${ }^{1}$

\begin{abstract}
INTRODUCTION COVID-19 disproportionately impacts patients aged $\geq 80$ years, yet few studies have focused on this population. We aimed to investigate the clinical characteristics and outcomes of very elderly patients with COVID-19 across three consecutive waves in Spain.

METHODS We retrospectively evaluated very elderly patients admitted with COVID-19 to a university hospital in Barcelona, Spain, across the three first waves. Main outcomes were ICU admission and 30-day mortality.

RESULTS From March 2020 to February 2021, 3105 patients diagnosed with COVID-19 were admitted. Of these, 655 (21\%) were very elderly patients, $50 \%$ were female and median age was 86 (83; 89) years. ICU admission and ICU-mortality rates were $11 \%$ and $42 \%$, respectively; male sex, respiratory rate $\geq 25$ breaths/min, $\mathrm{LDH} \geq 337.5 \mathrm{U} / \mathrm{L}$ and C-reactive protein $\geq 11.5 \mathrm{mg} / \mathrm{dL}$ were significantly associated with ICU admission in the multivariable analysis. Overall, 30-day mortality was 34\%. The ICU admission rate was significantly higher during the first wave compared to the third wave ( $16 \%$ vs $8 \% ; p=0.009$ ), whereas no significant differences in 30-day mortality were found between waves $(p=0.107)$.
\end{abstract}

CONCLUSIONS We observed an increase in the percentage of very elderly patients admitted to the ICU during the three first pandemic peaks. ICU admission more likely occurs in very elderly male patients with higher respiratory rate, with elevate $\mathrm{LDH}$ and $\mathrm{C}$-reactive protein. Overall, our 30-day mortality rate was lower compared to other series globally.

\author{
AFFILIATION \\ 1 Department of Pneumology, Hospital Clinic \\ of Barcelona, Barcelona, Spain \\ 2 Infectious Diseases Department, Hospital \\ Clinic of Barcelona, Barcelona, Spain
}

\section{CORRESPONDENCE TO}

Alex Soriano. Department of Pneumology, Hospital Clinic of Barcelona, Villarroel 170, Barcelona 08036, Spain. E-mail: asoriano@clinic.cat ORCID ID: https://orcid. org/0000-0002-9374-0811

Catia Cilloniz. Department of Pneumology, Hospital Clinic of Barcelona, Villarroel 170, Barcelona 08036, Spain. E-mail: catiacilloniz@yahoo.com ORCID ID: https:// orcid.org/0000-0002-4646-9838

\section{KEYWORDS}

outcomes, waves, pandemic, elderly, covid-19
Received: 4 September 2021
Revised: 29 September 2021 Accepted: 20 October 2021

\section{INTRODUCTION}

Since the beginning of the pandemic, Spain has been hit by five waves of COVID-19. Age was widely used as a prioritizing criterion for ICU admission, which has been one of the most controversial aspects of the pandemic thus far ${ }^{1}$. Numerous studies have found older age to be associated with higher risk of severe illness, complications, and mortality in COVID-192. Despite that patients aged $\geq 80$ years have distinct clinical features and risk factors, notably multiple comorbidities and polypharmacy ${ }^{3}$, there is little information on this specific population.

We aimed to describe and compare the clinical characteristics, complications, therapy and outcomes in very elderly patients with COVID-19 during the first three waves of the pandemic in Spain.

\section{METHODS}

We retrospectively evaluated all consecutive very elderly patients admitted to Hospital Clinic, Barcelona (Spain). All patients admitted $>48$ h with a definite diagnosis of COVID-19 (either confirmed by RT-PCR or fulfilling clinical criteria in place) between March 2020 and February 2021 were included. The primary outcome was ICU mortality. Secondary outcomes included length of hospital stay, early mortality (within 5 days of admission), 30-day mortality and need for mechanical ventilation. We divided the study population into three groups for the analysis: first wave (March to June 2020), second wave (July to November 2020) and third wave (December 2020 to February 2021).

Categorical variables were compared between the three groups using the $\chi^{2}$ test, while continuous variables with the Kruskal-Wallis test. In the event of a significant overall test, we conducted post hoc pairwise comparisons with Bonferroni correction. We examined the association of risk factors with ICU admission using logistic regression models. After bivariate analyses, we selected independent variables at a $p<0.25$. All the variables were put into a multivariable logistic regression analysis model. Final variable selection was performed using the backward stepwise selection method, except for period, which had to appear in the model. The Hosmer-Lemeshow goodness-of-fit test was performed to assess the overall fit of the final model. The receiver 
operating characteristic (ROC) curve was used to assess the discriminatory ability of the model to distinguish ICU patients from ward patients and is expressed as the area under the ROC curve (AUC). The level of significance was set at 0.05 (two-tailed). All analyses were performed using IBM SPSS Statistics version 26.0 (Armonk, New York, USA).

\section{RESULTS}

From March 2020 to February 2021, 3105 patients diagnosed with COVID-19 were admitted. A total of 655 (21\%) were very elderly patients and were included in our study [first wave 289/1447 (20\%); second wave 145/765 (19\%); third wave 221/893 (25\%)], 50\% were females, and median age was $86(83 ; 89)$ years.

The median time from symptoms to COVID-19 diagnosis was $5(2 ; 8)$ days. At least one comorbidity was present in $91 \%$ of patients, the most frequent of which were hypertension (74\%) and chronic heart disease (53\%) (Table 1).

Seventy-four (11\%) patients were admitted to the ICU,
$51 \%$ of whom during the first 48 h of hospital stay. Overall, 30-day mortality was 34\%.

No significant differences were observed regarding age, sex, or time from onset of symptoms to COVID-19 diagnosis between patients in the three waves (Table 1). A significantly higher proportion of COPD patients were admitted during the second (17\%) and third (14\%) waves, than in the first wave (8\%). No other significant differences were observed in other comorbidities between groups by wave (Table 1 ).

On admission, patients in the second and third waves more frequently presented tachypnea than patients in the first wave. Patients in the first wave presented the highest median levels of D-dimer. Overall, the use of drugs widely varied across waves, particularly in the case of hydroxychloroquine, lopinavir-ritonavir, azithromycin, and ceftriaxone (whose usage decreased with time), remdesivir and dexamethasone (increasingly used, Table 1).

ICU admission rates rose significantly, from $8 \%$ in the first wave to $16 \%$ in the third wave $(p=0.009)$. Forty-eight $(7 \%)$ patients received mechanical ventilation (5\% non-invasive

Table 1. Demographics and clinical characteristics of COVID-19 patients hospitalized during the three waves

\begin{tabular}{|c|c|c|c|c|c|}
\hline Characteristics & $\begin{array}{c}\text { Total } \\
(n=655) \\
\text { Median }(Q 1 ; Q 2) \\
\text { or } n(\%)\end{array}$ & $\begin{array}{c}\text { 1st wave } \\
(n=289) \\
\text { Median }(Q 1 ; Q 2) \\
\text { or } n(\%)\end{array}$ & $\begin{array}{c}\text { 2nd wave } \\
(n=145) \\
\text { Median }(Q 1 ; Q 2) \\
\text { or } n(\%)\end{array}$ & $\begin{array}{c}\text { 3rd wave } \\
(n=221) \\
\text { Median (Q1; Q2) } \\
\text { or } n(\%)\end{array}$ & $\mathbf{p}$ \\
\hline Age (years) & $86(83 ; 89)$ & $86(83 ; 89)$ & $85(82 ; 89)$ & $86(83 ; 89)$ & 0.468 \\
\hline Sex (male) & $327(50)$ & $134(46)$ & $73(50)$ & $120(54)$ & 0.205 \\
\hline Comorbidity & $594(91)$ & $271(94)$ & $129(89)$ & $194(88)$ & 0.050 \\
\hline Chronic heart disease & $348(53)$ & $155(54)$ & $76(52)$ & $117(53)$ & 0.969 \\
\hline Diabetes mellitus & $180(27)$ & 83 (29) & $34(23)$ & $63(29)$ & 0.467 \\
\hline Hematological disease & $53(8)$ & $20(7)$ & $14(10)$ & $19(9)$ & 0.581 \\
\hline Chronic kidney disease & $179(27)$ & $79(27)$ & $37(26)$ & $63(29)$ & 0.821 \\
\hline Chronic liver disease & $32(5)$ & $13(4)$ & $7(5)$ & $12(5)$ & 0.889 \\
\hline Hypertension & $485(74)$ & $218(75)$ & $102(70)$ & $165(75)$ & 0.505 \\
\hline Cancer & $163(25)$ & $66(23)$ & $35(24)$ & $62(28)$ & 0.391 \\
\hline Solid organ transplantation & $4(1)$ & $4(1)$ & $\mathrm{O}(0)$ & $\mathrm{O}(0)$ & 0.078 \\
\hline Chronic lung disease & $205(31)$ & $83(29)$ & $51(35)$ & $71(32)$ & 0.372 \\
\hline Asthma & $26(4)$ & $8(3)$ & $7(5)$ & $11(5)$ & 0.375 \\
\hline Bronchiectasis & $38(6)$ & $10(3)$ & $11(8)$ & $17(8)$ & 0.075 \\
\hline COPD & $81(12)$ & $24(8)$ & $25(17)$ & $32(14)$ & $0.014^{\mathrm{ab}}$ \\
\hline Pulmonary hypertension & $21(3)$ & $10(3)$ & $4(3)$ & $7(3)$ & 0.926 \\
\hline $\begin{array}{l}\text { Symptoms onset to COVID-19 } \\
\text { diagnosis (days) }\end{array}$ & $5(2 ; 8)$ & $5(2 ; 8)$ & $5(3 ; 8)$ & $5(2 ; 7)$ & 0.653 \\
\hline Heart rate (beats/min) & $89(80 ; 101)$ & $89(80 ; 102)$ & $89(81 ; 101)$ & $89(80 ; 100)$ & 0.877 \\
\hline Respiratory rate (breaths/min) & $23(20 ; 28)$ & $21(18 ; 28)$ & $24(20 ; 28)$ & $24(20 ; 28)$ & $0.001^{\mathrm{ab}}$ \\
\hline Oxygen saturation (\%) & $95(94 ; 97)$ & $95(93 ; 97)$ & $95.5(94 ; 97)$ & $95(94 ; 97)$ & 0.349 \\
\hline Diastolic blood pressure (mmHg) & $70(61 ; 78)$ & $69(60 ; 77)$ & $70(61.5 ; 80)$ & $70(62 ; 78)$ & 0.634 \\
\hline
\end{tabular}


Table 1. Continued

\begin{tabular}{|c|c|c|c|c|c|}
\hline Characteristics & $\begin{array}{c}\text { Total } \\
(n=655) \\
\text { Median (Q1; Q2) } \\
\text { or } n(\%)\end{array}$ & $\begin{array}{c}\text { 1st wave } \\
(n=289) \\
\text { Median }(Q 1 ; \text { Q2) } \\
\text { or } n(\%)\end{array}$ & $\begin{array}{c}\text { 2nd wave } \\
(n=145) \\
\text { Median (Q1; Q2) } \\
\text { or } n(\%)\end{array}$ & $\begin{array}{c}\text { 3rd wave } \\
(n=221) \\
\text { Median (Q1; Q2) } \\
\text { or } n(\%)\end{array}$ & $\mathbf{p}$ \\
\hline Systolic blood pressure (mmHg) & $127(114 ; 144)$ & $127(114 ; 145)$ & $128(117.5 ; 146)$ & $127(112 ; 141)$ & 0.578 \\
\hline Temperature $\left({ }^{\circ} \mathrm{C}\right)$ & $37.2(36.6 ; 37.8)$ & $37.2(36.5 ; 37.8)$ & $37.3(36.7 ; 38)$ & $37.1(36.6 ; 37.8)$ & 0.611 \\
\hline $\operatorname{ALT}(U / L)$ & $21(14 ; 33)$ & $21(13.5 ; 32)$ & $19(14 ; 34)$ & $21(13.5 ; 34)$ & 0.877 \\
\hline AST (U/L) & $34(25 ; 51)$ & $34(23 ; 52.5)$ & $32.5(25 ; 48)$ & $35(26 ; 53)$ & 0.386 \\
\hline Creatinine (mg/dL) & $1.18(0.89 ; 1.65)$ & $1.10(0.86 ; 1.62)$ & $1.13(0.87 ; 1.58)$ & $1.25(0.94 ; 1.83)$ & 0.056 \\
\hline D-dimer (ng/mL) & 1200 (700; 2950) & $1400(800 ; 4000)$ & $1100(600 ; 2400)$ & $1200(700 ; 2300)$ & $0.047^{c}$ \\
\hline Ferritin (ng/mL) & $443.5(185 ; 1003)$ & $464(196 ; 1088)$ & $436(167 ; 871)$ & $402.5(208 ; 1086)$ & 0.330 \\
\hline Glucose (mg/dL) & $129(105 ; 165)$ & $123(103 ; 163)$ & 135 (106.5; 158.5) & $133(108 ; 178)$ & 0.227 \\
\hline C-reactive protein $(\mathrm{mg} / \mathrm{dL})$ & $9(4 ; 16.7)$ & $8.7(4 ; 17.3)$ & $8.6(4.1 ; 16)$ & $9.1(3.8 ; 16.6)$ & 0.718 \\
\hline Procalcitonin (ng/mL) & $0.17(0.08 ; 0.46)$ & $0.18(0.08 ; 0.45)$ & 0.15 (0.09; 0.37) & 0.19 (0.09; 0.53) & 0.478 \\
\hline LDH (U/L) & 309 (240; 402) & 309 (237; 422) & $318(245 ; 391)$ & $300(235 ; 395)$ & 0.827 \\
\hline Troponin (ng/L) & $28.4(14.5 ; 77.3)$ & $26.5(13.6 ; 76.5)$ & $28.4(16.4 ; 68.5)$ & $34.6(15.4 ; 111.4)$ & 0.406 \\
\hline Leucocyte count $\left(\times 10^{9} / \mathrm{L}\right)$ & $7.05(5.24 ; 9.91)$ & $7.12(5.24 ; 10.03)$ & $6.59(5.08 ; 9.50)$ & $7.18(5.33 ; 9.71)$ & 0.344 \\
\hline Platelet count $\left(\times 10^{9} / \mathrm{L}\right)$ & $186(141 ; 245)$ & $188(143 ; 250)$ & $181(148 ; 232)$ & $186(131 ; 243)$ & 0.313 \\
\hline Lymphocyte count (×109/L) & $0.90(0.60 ; 1.20)$ & $0.85(0.60 ; 1.20)$ & $0.90(0.70 ; 1.20)$ & $0.90(0.60 ; 1.20)$ & 0.463 \\
\hline Neutrophil-to-lymphocyte ratio & $6.2(3.7 ; 10.3)$ & $6.3(3.8 ; 10.9)$ & $5.3(3.4 ; 9.8)$ & $6.4(4 ; 9.9)$ & 0.117 \\
\hline $\begin{array}{l}\text { Noninvasive mechanical } \\
\text { ventilation }\end{array}$ & $33(5)$ & $8(3)$ & $9(6)$ & $16(7)$ & 0.056 \\
\hline Invasive mechanical ventilation & $15(2)$ & $5(2)$ & $7(5)$ & $3(1)$ & 0.066 \\
\hline LOS (days) & $8(5 ; 14)$ & $8(4 ; 13)$ & $9(6 ; 14)$ & $9(5 ; 15)$ & $0.011^{a b}$ \\
\hline ICU admission & $74(11)$ & $22(8)$ & $16(11)$ & $36(16)$ & $0.009^{b}$ \\
\hline Hydroxychloroquine & $220(34)$ & $220(76)$ & $\mathrm{O}(0)$ & $\mathrm{O}(0)$ & $<0.001^{a b}$ \\
\hline Lopinavir/ritonavir & $157(24)$ & $157(54)$ & $\mathrm{O}(0)$ & $\mathrm{O}(0)$ & $<0.001^{\text {ab }}$ \\
\hline Azithromycin & $257(39)$ & $224(78)$ & $15(10)$ & $18(8)$ & $<0.001^{\text {ab }}$ \\
\hline Ceftriaxone & 349 (53) & $170(59)$ & $74(51)$ & $105(48)$ & $0.033^{b}$ \\
\hline Remdesivir & $70(11)$ & $4(1)$ & $33(23)$ & $33(15)$ & $<0.001^{a b}$ \\
\hline Corticosteroids & 389 (59) & $123(43)$ & $99(68)$ & $167(76)$ & $<0.001^{\text {ab }}$ \\
\hline Dexamethasone & $223(34)$ & $5(2)$ & $76(52)$ & $142(64)$ & $<0.001^{a b}$ \\
\hline Methylprednisolone & $206(31)$ & $105(36)$ & $34(23)$ & $67(30)$ & $<0.001^{a}$ \\
\hline Prednisone & $112(17)$ & $49(17)$ & $23(16)$ & $40(18)$ & 0.166 \\
\hline ICU mortality ${ }^{d}$ & $31(42)$ & $12(55)$ & $4(25)$ & $15(42)$ & 0.190 \\
\hline Early mortality & $99(15)$ & $64(22)$ & $12(8)$ & $23(10)$ & $<0.001^{\text {ab }}$ \\
\hline 30-day mortality & $223(34)$ & $111(38)$ & $43(30)$ & $69(31)$ & 0.107 \\
\hline
\end{tabular}

COPD: chronic obstructive pulmonary disease. ICU: intensive care unit. LOS: length of hospital stay. Q1: first quartile. Q3: third quartile. LDH: lactate dehydrogenase. a p<0.05 for comparison between the groups of 1 st wave and 2 nd wave. $b$ p $<0.05$ for comparison between the groups of 1 st wave and 3rd wave. c p $<0.05$ for comparison between the groups of 2 nd wave and 3 rd wave. d 74 patients were used to calculate the percentages (22 patients in the 1st wave, 16 in the 2nd wave, and 36 in the 3rd wave).

and $2 \%$ invasive mechanical ventilation), with no differences between waves.

Early mortality was 15\% (99), with a significant decrease, from $22 \%$ in the first wave to $10 \%$ in the third wave $(p<0.001)$. ICU mortality was $42 \%$ (31), with no differences between waves. There were 223 (34\%) patients who died at 30 days after admission, with no differences between waves. Male sex, respiratory rate $\geq 25$ breaths/min, $L D H \geq 337.5$ $\mathrm{U} / \mathrm{L}$ and $\mathrm{C}$-reactive protein $\geq 11.5 \mathrm{mg} / \mathrm{dL}$ were significantly associated with ICU admission in the multivariable analysis 
Table 2. Significant univariate logistic regression analysis for variables associated with ICU admission and independent predictors of ICU admission determined by multivariable logistic regression analysis ${ }^{\mathrm{a}}$

\begin{tabular}{|c|c|c|c|c|c|c|c|c|c|}
\hline \multirow[t]{2}{*}{ Variable } & \multicolumn{3}{|c|}{ Univariate $^{\text {b }}$} & \multicolumn{3}{|c|}{ Multivariable $(n=279)^{\mathrm{cd}}$} & \multicolumn{3}{|c|}{ Multivariable $(n=279)^{c e}$} \\
\hline & OR & $95 \% \mathrm{CI}$ & $\mathbf{p}$ & OR & $95 \% \mathrm{CI}$ & $\mathbf{p}$ & OR & $95 \% \mathrm{CI}$ & $\mathbf{p}$ \\
\hline Period & & & 0.028 & & & 0.080 & & & 0.076 \\
\hline First wave (Ref.) & 1 & - & - & 1 & - & - & 1 & - & - \\
\hline Second wave & 1.09 & $0.54-2.22$ & 0.811 & 0.87 & $0.37-2.06$ & 0.752 & 0.93 & $0.40-2.16$ & 0.874 \\
\hline Third wave & 2.12 & $1.16-3.88$ & 0.015 & 2.03 & $0.93-4.44$ & 0.076 & 2.08 & $0.98-4.43$ & 0.058 \\
\hline Male sex & 3.06 & $1.73-5.40$ & $<0.001$ & 2.41 & $1.19-4.88$ & 0.014 & 2.30 & $1.16-4.53$ & 0.017 \\
\hline Heart rate $(+1 \text { beats } / \min )^{f}$ & 1.01 & $1.00-1.03$ & 0.052 & - & - & - & - & - & - \\
\hline $\begin{array}{l}\text { Respiratory rate }(+1 \\
\text { breaths } / \mathrm{min})^{f}\end{array}$ & 1.15 & $1.10-1.21$ & $<0.001$ & 1.13 & $1.07-1.20$ & $<0.001$ & - & - & - \\
\hline $\begin{array}{l}\text { Respiratory rate } \geq 25 \\
\text { breaths/ming }\end{array}$ & 5.60 & $3.17-9.89$ & $<0.001$ & - & - & - & 4.28 & $2.24-8.18$ & $<0.001$ \\
\hline Oxygen saturation $(+1 \%)^{f}$ & 0.90 & $0.83-0.97$ & 0.009 & - & - & - & - & - & - \\
\hline $\begin{array}{l}\text { Diastolic blood pressure }(+1 \\
\mathrm{mmHg})^{\text {th }}\end{array}$ & 0.96 & $0.94-0.99$ & 0.001 & - & - & - & - & - & - \\
\hline $\begin{array}{l}\text { Systolic blood pressure }(+1 \\
\mathrm{mmHg})^{f}\end{array}$ & 0.99 & $0.98-1.00$ & 0.123 & - & - & - & - & - & - \\
\hline Temperature $\left(+1^{\circ} \mathrm{C}\right)^{f}$ & 1.23 & $0.92-1.64$ & 0.154 & - & - & - & - & - & - \\
\hline $\operatorname{ALT}(+1 \cup / L)^{f}$ & 1.01 & $1.00-1.02$ & 0.059 & - & - & - & - & - & - \\
\hline AST $(+1 U / L)^{\text {th }}$ & 1.02 & $1.00-1.03$ & 0.011 & - & - & - & - & - & - \\
\hline Creatinine $(+1 \mathrm{mg} / \mathrm{dL})^{\mathrm{f}}$ & 1.15 & $0.92-1.44$ & 0.208 & - & - & - & - & - & - \\
\hline Glucose $(+1 \mathrm{mg} / \mathrm{dL})^{\mathrm{f}}$ & 1.01 & $1.00-1.01$ & 0.001 & - & - & - & - & - & - \\
\hline $\mathrm{LDH}(+1 \mathrm{U} / \mathrm{L})^{\mathrm{f}}$ & 1.01 & $1.00-1.01$ & $<0.001$ & 1.01 & $1.00-1.01$ & 0.001 & - & - & - \\
\hline $\mathrm{LDH} \geq 337.5 \mathrm{U} / \mathrm{L}^{\mathrm{g}}$ & 3.92 & $2.24-6.87$ & $<0.001$ & - & - & - & 2.41 & $1.22-4.76$ & 0.011 \\
\hline $\begin{array}{l}\text { C-reactive protein }(+1 \mathrm{mg} / \\
\mathrm{dL})^{\mathrm{f}}\end{array}$ & 1.08 & $1.05-1.12$ & $<0.001$ & 1.06 & $1.01-1.10$ & 0.010 & - & - & - \\
\hline $\begin{array}{l}\text { C-reactive protein } \geq 11.5 \\
\mathrm{mg} / \mathrm{dL}^{\mathrm{g}}\end{array}$ & 3.49 & $2.03-6.00$ & $<0.001$ & - & - & - & 2.38 & $1.22-4.67$ & 0.011 \\
\hline $\begin{array}{l}\text { Neutrophil-to-lymphocyte } \\
\text { ratio }(+1)^{f}\end{array}$ & 1.07 & $1.03-1.12$ & $<0.001$ & - & - & - & - & - & - \\
\hline
\end{tabular}

ALT: indicates alanine transaminase. AST: aspartate transaminase. Cl: confidence interval. LDH: lactate dehydrogenase. OR: odds ratio. Data are shown as estimated ORs (95\% Cls) of the explanatory variables in the ICU admission group. The OR represents the odds that the presence of ICU admission will occur given exposure of the explanatory variable, compared to the odds of the outcome occurring in the absence of that exposure; for continuous predictors, the OR represents the increase in odds of the outcome of interest with every one unit increase in the input variable. The $p$-value is based on the null hypothesis that all ORs relating to an explanatory variable equal unity (no effect). aPatients who were not admitted to ICU and with a DNR were excluded. bThe variables analyzed in the univariate analysis were sex, diabetes mellitus, chronic heart disease, chronic kidney disease, chronic liver disease, hypertension, COPD, heart rate, respiratory rate, oxygen saturation, diastolic blood pressure, systolic blood pressure, temperature, ALT, AST, creatinine, glucose, LDH, C-reactive protein, leucocytes, neutrophil-to-lymphocyte ratio, and platelets. cAdjusted for period of admission. dHosmer-Lemeshow goodness-of-fit test, $p=0.684$. Area under the ROC curve, AUC=0.82 (95\% Cl: $0.76-0.88$ ). e Hosmer-Lemeshow goodness-of-fit test, $\mathrm{p}=0.086$. Area under the ROC curve, $\mathrm{AUC}=0.80(95 \% \mathrm{Cl}: 0.73-0.87) . \mathrm{f}^{\prime}+1^{\prime}$ indicates an increase by one unit. gCut-off obtained from ROC curve. $\mathrm{hVariable}$ excluded of multivariable analysis because of collinearity with another significant variable.

(Table 2). The AUC was 0.80 (95\% Cl: 0.73-0.87) for the predictive model.

\section{DISCUSSION}

In accordance with data from other regions ${ }^{4,5}$, where elderly patients were reported to be the population most affected by COVID-19, the burden of COVID-19 in very elderly patients remained high throughout the three first waves in Spain. The proportion of patients with COPD increased between the first and third waves. Despite the reported overall relatively low incidence of COVID-19 in COPD patients (1.1-10\%), COPD patients have an increased risk of severe disease and poor outcomes ${ }^{8}$. Thus, the increase in COPD across waves may be explained because this population may have taken isolation measures more seriously and, consequently, reduced their rates of infection, provided that it was made clear from the early stages of the pandemic that SARS-CoV-2 severely affected the lungs. Also, the use of inhaled corticosteroids may 
offer a protective effect in these patients, as recently reported ${ }^{9}$.

In our study, $91 \%$ of our patients presented at least one comorbidity, $15 \%$ of the patients died in the first 5 days after admission, and ICU mortality was 42\%, which shows the disproportionate impact of COVID-19 on these patients; this increased impact has also been widely reported for the elderly population though not specifically in very elderly patients ${ }^{10}$. Early recognition of severe COVID-19 in very elderly patients may allow prompt complication management, thus improving outcomes or optimizing comfort in patients who are not candidates for aggressive therapeutic measures. During the pandemic peaks, we observed a significant increase in the use of remdesivir and corticosteroids, whereas hydroxycloroquine, lopinavir/ ritonavir, and azythromycin were progressively abandoned, which is in line with the results of the main platform clinical trials on COVID-19 (i.e. WHO Solidarity trial ${ }^{11}$, RECOVERY ${ }^{12}$, REMAP-CAP $\left.{ }^{13}\right)$. Overall, $11 \%$ of very elderly patients were admitted to the ICU, with rates increasing between the first and third waves (8-16\%), which are likely related to the availability of ICU beds. During the first wave, the Spanish health system, including ICUs, was largely overwhelmed and prioritization criteria that included advanced age or reduced functionality in nursery homes residents were implemented in many hospitals ${ }^{1}$. We found that male sex, respiratory rate, and $\mathrm{C}$-reactive protein were associated to a higher likelihood of ICU admission, which has already been reported ${ }^{5,6,10,14}$. Meanwhile, 30-day mortality rates, although remarkably lower overall (34\%) compared to other series worldwide $(46-54 \%)^{2,14,15}$, are strikingly high figures that highlight the vulnerability of very elderly patients to COVID-19 and therefore the relevance of preventive measures.

\section{Strengths and limitations}

The strengths of this study include the large sample size, the special focus on very elderly patients, and the information on three consecutive COVID-19 wave peaks. The study does, however, have some limitations that need to be addressed. The data were collected from a single academic teaching hospital in Spain; it may not be possible to extrapolate results to patients admitted to different hospitals or in other countries. Second, data on quality of life, frailty, and/or functional status were not recorded, which may have led to an underestimation of their potential predictive value.

\section{CONCLUSIONS}

We observed an increase in the percentage of very elderly patients admitted to the ICU during the three first pandemic peaks. ICU admission more likely occurs in very elderly male patients with higher respiratory rate, with elevated LDH and C-reactive protein. Overall, our 30-day mortality rate was lower compared to other series globally.

\section{ACKNOWLEDGEMENTS}

We are indebted to all participating medical and nursing colleagues for their assistance and cooperation in this study.

\section{CONFLICTS OF INTEREST}

The authors have completed and submitted the ICMJE Form for Disclosure of Potential Conflicts of Interest and none was reported.

\section{FUNDING}

This work received a grant from a crowd funding organized by Hospital Clínic and IDIBAPS. C. Cillóniz is the recipient of the SEPAR fellowship 2018, a grant 2019 from the Fondo de Investigación Sanitaria (PI19/00207), and the SEPAR fellowship 'Programa Mentor'. Our group is recognized by the AGAUR (Project 2017SGR1432) of the Catalan Health Agency.

\section{ETHICAL APPROVAL AND INFORMED CONSENT}

The study was approved by the local Institutional Review Board (HCB/2020/0273). The need for written informed consent was waived due to the non-interventional design of the study.

\section{DATA AVAILABILITY}

The data supporting this research are available from the authors on reasonable request.

\section{AUTHORS' CONTRIBUTIONS}

CC, FM, GD and AS conceived the study. CC, FM, GD and $J G$ executed the search and extracted data. FM, GD and $A G$ performed the analysis of data, with inputs from CC, MC, PP, NC, VR, AT, CG and AS. All authors contributed to the interpretation of data. CC, FM, GD and AS wrote the initial draft of the manuscript. All authors contributed to the critical revision of the manuscript for important intellectual content and approved the final version. AS and CC are guarantors for the study.

\section{PROVENANCE AND PEER REVIEW}

Not commissioned; externally peer reviewed.

\section{REFERENCES}

1. Jaziri R, Alnahdi S. Choosing which COVID-19 patient to save? The ethical triage and rationing dilemma. Ethics Med Public Health. 2020;15:100570. doi:10.1016/j.jemep.2020.100570

2. Ramos-Rincon JM, Buonaiuto V, Ricci M, et al. Clinical Characteristics and Risk Factors for Mortality in Very Old Patients Hospitalized With COVID-19 in Spain. J Gerontol A Biol Sci Med Sci. 2021;76(3):e28-e37. doi:10.1093/gerona/glaa243

3. Liu Z, Wu D, Han X, et al. Different characteristics of critical COVID-19 and thinking of treatment strategies in non-elderly and elderly severe adult patients. Int Immunopharmacol. 2021;92:107343. doi:10.1016/j.intimp.2020.107343 
4. Saito S, Asai $Y$, Matsunaga N, et al. First and second COVID-19 waves in Japan: A comparison of disease severity and characteristics. J Infect. 2021;82(4):84-123. doi:10.1016/j.jinf.2020.10.033

5. Liu X, Zhou H, Zhou Y, et al. Risk factors associated with disease severity and length of hospital stay in COVID-19 patients. J Infect. 2020;81(1):e95-e97. doi:10.1016/j.jinf.2020.04.008

6. Tomlins J, Hamilton F, Gunning S, Sheehy C, Moran E, MacGowan A. Clinical features of 95 sequential hospitalised patients with novel coronavirus 2019 disease (COVID-19), the first UK cohort. J Infect. 2020;81(2):e59-e61. doi:10.1016/j.jinf.2020.04.020

7. Rentsch CT, Kidwai-Khan F, Tate JP, et al. Covid-19 Testing, Hospital Admission, and Intensive Care Among 2,026,227 United States Veterans Aged 54-75 Years. medRxiv. Preprint posted online April 14, 2020. doi:10.1101/2020.04.09.20059964

8. Alqahtani JS, Oyelade T, Aldhahir AM, et al. Prevalence, Severity and Mortality associated with COPD and Smoking in patients with COVID-19: A Rapid Systematic Review and Meta-Analysis. PLoS One. 2020;15(5):e0233147. doi:10.1371/journal.pone.0233147

9. Yu LM, Bafadhel M, Dorward J, et al. Inhaled budesonide for COVID-19 in people at high risk of complications in the community in the UK (PRINCIPLE): a randomised, controlled, openlabel, adaptive platform trial. Lancet. 2021;398(10303):843-855. doi:10.1016/SO140-6736(21)01744-X

10. Onder G, Rezza G, Brusaferro S. Case-Fatality Rate and Characteristics of Patients Dying in Relation to COVID-19 in Italy. JAMA. 2020;323(18):1775-1776. doi:10.1001/jama.2020.4683

11. WHO Solidarity Trial Consortium. Repurposed Antiviral Drugs for Covid-19 - Interim WHO Solidarity Trial Results. N Engl J Med. 2021;384(6):497-511. doi:10.1056/NEJMoa2023184

12. RECOVERY Collaborative Group. Dexamethasone in Hospitalized Patients with Covid-19. N Engl J Med. 2021;384(8):693-704. doi:10.1056/NEJMoa2021436

13. The Writing Committee for the REMAP-CAP Investigators. Effect of Hydrocortisone on Mortality and Organ Support in Patients With Severe COVID-19: The REMAP-CAP COVID-19 Corticosteroid Domain Randomized Clinical Trial. JAMA. 2020;324(13):1317-1329. doi:10.1001/jama.2020.17022

14. Richardson S, Hirsch JS, Narasimhan M, et al. Presenting Characteristics, Comorbidities, and Outcomes Among 5700 Patients Hospitalized With COVID-19 in the New York City Area. JAMA. 2020;323(20):2052-2059. doi:10.1001/jama.2020.6775

15. Zerah L, Baudouin É, Pépin M, et al. Clinical Characteristics and Outcomes of 821 Older Patients With SARSCov-2 Infection Admitted to Acute Care Geriatric Wards. J Gerontol A Biol Sci Med Sci. 2021;76(3):e4-e12. doi:10.1093/gerona/glaa210 